\title{
Evaluation of lay skills in cardiopulmonary resuscitation
}

\author{
P M VAN KALMTHOUT, P A J SPETH, J R RUTTEN, J TH CH VONK \\ From the Department of Cardiology, St Radboud University Hospital, Nijmegen, The Netherlands
}

SUMMARY The theoretical knowledge and practical performance of 166 lay people attending a short cardiopulmonary resuscitation course were evaluated according to the American Heart Association standards. Before tt course no participant was able to perform even a bad attempt at cardiopulmonary resuscitation. Theoretical knowledge was good at the end of the course and at the refresher course six months later. At the end of the initial course $65 \%(57 / 88)$ of the participants examined could adequately compress and ventilate the manikin. After six months $44 \%(30 / 68)$ could perform resuscitation adequately. Women were as proficient as men, and elderly people in general were as proficient as the younger ones. The skill of carotid artery palpation was surprisingly well retained after six months. Data on pulmonary ventilation and cardiac massage were recorded simultaneously on a recording resuscitation manikin. When these objective data were compared with the American Heart Association standards only a few participants were able to perform correct cardiopulmonary resuscitation. The number of compressions and ventilations per minute were often insufficient. A large discrepancy between self, subjective, and objective assessment of cardiopulmonary resuscitation knowledge and performance was found.

The importance of a rapid diagnosis, an immediate call for help, an adequate rate of cardiac massage, and a reduction in the time needed for ventilation should be emphasised at these courses. Refresher courses should be provided at least twice a year.

Since Kouwenhoven published his article on closed chest cardiac massage in $1960^{1}$ cardiopulmonary resuscitation has been used by doctors and later by more and more lay people in cases of cardiopulmonary arrest. Both doctors and non-medical personnel have had to be trained in the technique of resuscitation. In $1974^{2}$ and $1980^{3}$ the American Heart Association published training programmes and guidelines.

To date more than 12 million adults in the USA have received instructions in cardiopulmonary resuscitation according to the American Heart Association standards. In the Netherlands (14.6 million inhabitants) several hundred thousand adults have been trained under the guidance of the Netherlands Heart Foundation (J van Drenth, personal communication). Only a few reports are available about the results of training lay people in cardiopulmonary resuscitation

Requests for reprints to Dr P M van Kalmthout, Department of Cardiology, St Radboud University Hospital, PO Box 9101, 6500 HB Nijmegen, The Netherlands.

Accepted for publication 15 January 1985 and about how well knowledge and practical performance are retained after some time. ${ }^{4-7}$

We evaluated the theoretical knowledge and practical performance of lay people before and after instruction in cardiopulmonary resuscitation and compared the results with those after six months to determine how well these skills had been retained.

\section{Subjects and methods}

CARDIOPULMONARY RESUSCITATION COURSE

By advertising in regional papers and with the aid of the local branch of the Netherlands Heart Foundation, the citizens of Nijmegen - a university city with 140000 inhabitants-and its surrounding villages were invited to attend a cardiopulmonary resuscitation course. The course consisted of three evening sessions of theoretical and practical instruction. A fourth evening was designated for a 20 multiple choice questionnaire to evaluate theoretical knowledge. The practical cardiopulmonary resuscitation performance was evaluated by one of the instructors. 
A doctor gave two one hour lectures 'on the theoretical principles of cardiopulmonary resuscitation. The practical instructions were given by paramedical cardiopulmonary resuscitation instructors and consisted of four one hour sessions using a non-recording Resusci Anne manikin. All participants received an illustrated instruction booklet, which gives comprehensive information on cardiopulmonary resuscitation. ${ }^{8}$ If the candidate completed the course and passed both the theoretical and practical tests, a certificate of proficiency was given with the date of the refresher course printed on it. Every six months three identical refresher courses consisting of $\mathbf{5 0}$ minutes of theoretical and 50 minutes of practical instruction were provided.

\section{STUDY}

During the study period from September 1982 until March 1984, 10 participants were randomly selected at the beginning of the course, 88 at the end of the course, and 68 before the start of the refresher course. All these participants were asked to answer a multiple choice questionnaire on diagnosis, pulmonary ventilation, and cardiac massage. Throughout the study they had to estimate their own level of theoretical knowledge and practical performance on a 1-10 scale. In addition, they performed cardiopulmonary resuscitation on a recording manikin (Laërdal Recording Resusci Anne, Asmund Laërdal, Stavanger, Norway) for at least two minutes to assess their performance objectively. Their practical performance was also judged subjectively by one of us and was scored on the following items: (a) psychomotor performance (establishing unresponsiveness, checking both carotid arteries, checking breathing, checking mydriasis); (b) adequate call for help (correct phone number and diagnosis); and (c) adequate performance of cardiopulmonary resuscitation (position of the hands, massage technique, massage rate, overstretching of the head, depth of ventilation, leakage of air).

Practical performance assessed by subjective data was considered as adequate when the participant could palpate the carotid artery on both sides of the manikin and perform about 15 cardiac compressions at a rate of 50-70/minute with adequate depth and two ventilations with adequate volume between two massage cycles.

The objective data from the recording manikin tape were analysed afterwards. Data on massage and ventilation were derived from the last full minute recorded, and comprised: (a) time from "go ahead sign" until first act of cardiopulmonary resuscitation; $(b)$ number per minute and depth of compressions (standard 5070/minute and $38-51 \mathrm{~mm}$ respectively); (c) number per minute and depth of ventilations (standard $\geqslant 5 /$ minute, 0.8-1.61 respectively); (d) rate of compres- sions (standard 70-90/minute); and (e) total time per minute (in seconds) needed for ventilation (the time between two massage cycles was recorded). In addition the ability to palpate and count correctly the instructor's carotid artery pulse on both sides was assessed.

Practical performance assessed by objective data was considered adequate when the examiner's carotid artery was correctly palpated $\leqslant 1$ minute, the manikin was ventilated $\geqslant 5$ times/minute with volumes of 0.8 1.61 , and 50-70 cardiac compressions/minute were performed with a depth of $38-51 \mathrm{~mm}$.

In the three groups the self estimated knowledge and practical performance of the different skills were compared with the subjective and objective assessments. Data were analysed by the university mathematical statistical department.

\section{Results}

\section{POPULATION}

From 1979 to 1984 , nearly 3000 people attended their first cardiopulmonary resuscitation course in $\mathrm{Nij}$ megen. Fifty six per cent came from the main town and $44 \%$ from the surrounding villages. The Figure shows the age and sex distribution of the total population. There were $73 \%$ women and $27 \%$ men. The mean age was 38 (range 13-73) years. Of those who

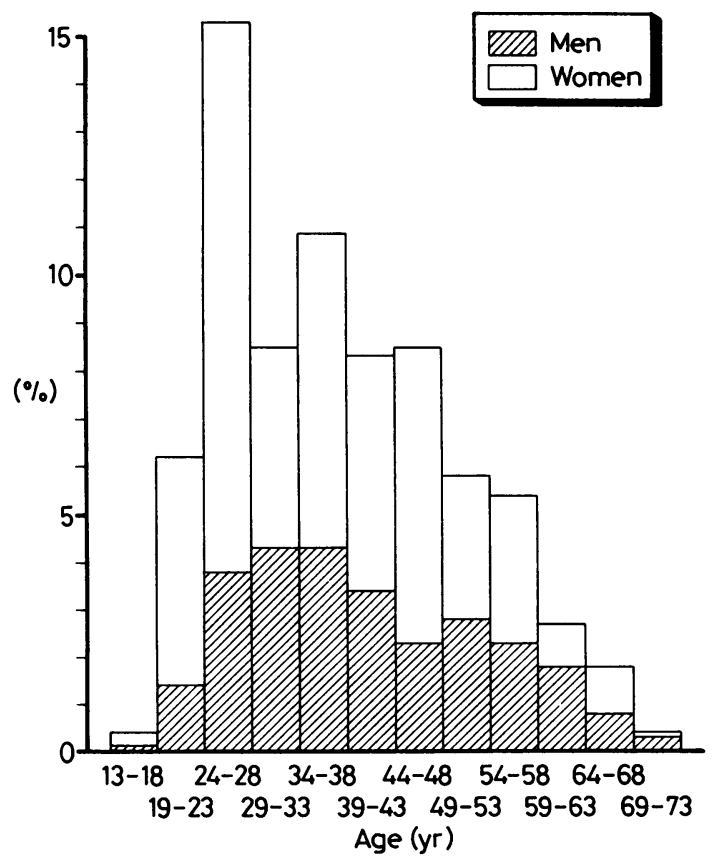

Figure Age and sex distribution of participants attending a cardiopulmonary resuscitation course between 1979 and 1984. 
Table 1 Age and sex distribution of the participants in the study before and after the course and at the refresher course

\begin{tabular}{|c|c|c|c|c|c|c|c|}
\hline & \multirow{2}{*}{$\begin{array}{l}\text { No of } \\
\text { participants }\end{array}$} & \multirow[t]{2}{*}{ Women } & \multirow[t]{2}{*}{ Men } & \multicolumn{2}{|c|}{ Mean $(S D)$ age $(y r)$} & \multicolumn{2}{|c|}{ No of participants aged } \\
\hline & & & & Women & Men & $\leqslant 40 y r$ & $>40 \mathrm{yr}$ \\
\hline $\begin{array}{l}\text { Before } \\
\text { After } \\
\text { Refresher course } \\
\text { Total }\end{array}$ & $\begin{array}{r}10 \\
88 \\
68 \\
166\end{array}$ & $\begin{array}{r}7 \\
56 \\
38 \\
101\end{array}$ & $\begin{array}{r}3 \\
32 \\
30 \\
65\end{array}$ & $\begin{array}{l}34(12) \\
37(11) \\
36(9) \\
35(11)\end{array}$ & $\begin{array}{l}38(12) \\
38(10) \\
42(2) \\
38(11)\end{array}$ & $\begin{array}{r}5 \\
63 \\
48 \\
116\end{array}$ & $\begin{array}{r}5 \\
25 \\
20 \\
50\end{array}$ \\
\hline
\end{tabular}

attended the course, only $30 \%$ returned at the first refresher course; this proportion decreased to $12 \%$ for those attending a fifth refresher course after two and a half years. Table 1 shows the age and sex distribution of the study groups. There was no difference between each of the groups and the total population regarding age and sex distribution. Most people attended the course because of social motivation and a few because of illness in their family.

\section{THEORETICAL KNOWLEDGE}

Theoretical knowledge was evaluated by the multiple choice questionnaire, and was considered adequate when more than $70 \%$ of the questions were answered correctly. Before the course theoretical knowledge was inadequate in all the participants but at the end of the course and before the refresher course this was good in both groups (Table 2), although a slightly lower figure was recorded at the refresher course. At the refresher course, a discrepancy was noted between self assessment and objective assessment scores. There was no difference in theoretical knowledge between older and younger people.

\section{PRACTICAL PERFORMANCE}

Subjective data

Before the cardiopulmonary resuscitation course when the participants were asked to help someone who had suddenly collapsed, none knew how to establish a proper diagnosis of cardiopulmonary arrest or how to perform adequate ventilation or massage or both (Table 3).

Table 2 Percentage of participants in whom theoretical knowledge was assessed as adequate before and after the course and at the refresher course. Figures in parentheses are numbers of subjects

\begin{tabular}{lcll}
\hline & $\begin{array}{l}\text { Before } \\
(n=10)\end{array}$ & $\begin{array}{l}\text { After } \\
(n=88)\end{array}$ & $\begin{array}{l}\text { Refresher course } \\
(n=68)\end{array}$ \\
\hline Skills tested: & $20(2)$ & $67(59)$ & $66(45)$ \\
$\quad$ Diagnosis & $0(0)$ & $38(33)$ & $22(15)$ \\
Ventilation & $0(0)$ & $68(60)$ & $21(14)$ \\
$\quad$ Massage & $10(1)$ & $93(82)$ & $71(48)$ \\
Objective assessment & $20(2)$ & $93(82)=94(64)$ \\
Self assessment & $20 . . .2$
\end{tabular}

By the end of the course cardiopulmonary arrest was correctly diagnosed by $74 \%$ of participants but at the refresher course only $50 \%$ managed to do so. The call for help was given immediately after establishing a diagnosis by only $55 \%$ at the end of the course and by $46 \%$ at the refresher course, but $88 \%$ and $70 \%$ respectively achieved this within one minute after starting cardiopulmonary resuscitation. Ventilation was correctly performed by $20 \%$ of the participants before the cardiopulmonary resuscitation course, by $51 \%$ at the end of the course, and by only $37 \%$ at the refresher course.

Only $35 \%$ and $38 \%$ of participants respectively could correctly perform cardiac massage at the end of the course and at the refresher course. Too slow a rate was the most frequent fault in $35 \%$ and $40 \%$ of participants respectively at the end of the course and at the refresher course. A subjective assessment of adequate cardiopulmonary resuscitation at the end of the course and at the refresher course was thus performed in $65 \%$ and $44 \%$ of participants respectively, which contrasts with figures of $94 \%$ and $82 \%$ by self assessment. If the time since the last course was more than one year, the proportion fell further to $38 \%$ at the refresher course.

\section{Objective data}

At the end of the course and at the refresher course the mean time from the "go ahead" sign to the first act was $42 \mathrm{~s}$ (range 10-127, 90\% between 15-80 s), but in both groups it took two candidates two minutes before they actually started cardiopulmonary resusci-

Table 3 Percentage of participants in whom practical performance was assessed as adequate before and after course and at refresher course. Figures in parentheses are numbers of subjects

\begin{tabular}{lrll}
\hline & $\begin{array}{l}\text { Before } \\
(n=10)\end{array}$ & $\begin{array}{l}\text { After } \\
(n=88)\end{array}$ & $\begin{array}{l}\text { Refresher course } \\
(n=68)\end{array}$ \\
\hline Skills tested: & & & \\
Diagnosis & $0(0)$ & $74(65)$ & $50(34)$ \\
Ventilation & $20(2)$ & $51(45)$ & $37(25)$ \\
Massage & $0(0)$ & $35(31)$ & $38(26)$ \\
Subjective assessment & $0(0)$ & $65(57)$ & $44(30)$ \\
Self assessment & $0(0)$ & $94(83)$ & $82(56)$ \\
\hline
\end{tabular}


Table 4 Objective assessment of performance of participants in carrying out pulmonary ventilation and cardiac massage before and after the course and at the refresher course. Figures are percentages with numbers of subjects in parentheses

$$
\begin{array}{lll}
\begin{array}{l}
\text { Before } \\
(n=10)
\end{array} & \begin{array}{l}
\text { After } \\
(n=88)
\end{array} & \begin{array}{l}
\text { Refresher } \\
\text { course } \\
(n=68)
\end{array}
\end{array}
$$

\begin{tabular}{|c|c|c|c|}
\hline \multicolumn{4}{|c|}{ Pulmonary ventilation } \\
\hline $\begin{array}{l}\geqslant 5 \text { ventilations/minute } \\
\text { Adequate volume }(0.8-1.6 \mathrm{l})\end{array}$ & $\begin{array}{l}0(0) \\
0(0)\end{array}$ & $\begin{array}{l}64(56) \\
35(31)\end{array}$ & $\begin{array}{l}38(26) \\
34(23)\end{array}$ \\
\hline $\begin{array}{l}\quad 6 \mathrm{~s} \\
6-10 \mathrm{~s} \\
>10 \mathrm{~s} \\
\text { Adequate ventilation }\end{array}$ & $\begin{array}{l}=(\text { ( ) } \\
\overline{0}(-)\end{array}$ & $\begin{array}{l}25(22) \\
45(40) \\
30(26) \\
48\end{array}$ & $\begin{array}{l}12(8) \\
40(27) \\
48(33) \\
28\end{array}$ \\
\hline No of compressions/min Cardia & massage & & \\
\hline $\begin{array}{l}(50-70 / \mathrm{min}) \\
\text { Rate }(70-90 / \mathrm{min}) \\
\text { Depth }(38-51 \mathrm{~mm}) \\
\text { Adequate massage }\end{array}$ & $\begin{array}{r}0 \\
0 \\
25 \\
0\end{array}$ & $\begin{array}{r}25 \\
42 \\
32 \\
5\end{array}$ & $\begin{array}{r}22 \\
40 \\
50 \\
3\end{array}$ \\
\hline
\end{tabular}

tation. At the end of the course and at the refresher course $90 \%$ and $83 \%$ respectively were able to palpate the carotid artery $\leqslant 1$ minute, two thirds of them succeeding within half a minute.

Table 4 gives details of the ventilation technique. Before the course the participants had no knowledge of ventilation. By the end $64 \%$ were able to give five or more ventilations in the last recorded minute, but only $35 \%$ were ventilating with adequate volume $(0.8-1.61)$. At the refresher course only $38 \%$ ventilated $\geqslant 5$ times per minute, again only one third ventilating with adequate volume. The mean time needed for two "quick" ventilations varied from $8 \mathrm{~s}$ (range 4-24 s) to $10 \mathrm{~s}$ (range 6-43 s) respectively; $30 \%$ at the end of the course and $48 \%$ at the refresher course needed more than $10 \mathrm{~s}$.

Table 4 also gives details concerning cardiac massage. Before the course no participant could massage properly. Only about $25 \%$ of both groups delivered $50-70$ compressions/minute, although $42 \%$ of the participants did this at an adequate rate. A high proportion of both trained groups $(95 \%$ and $97 \%$ respectively) could not perform massage adequately.

\section{COMPARISON OF ASSESSMENTS}

Finally, we compared the participants' own assessment, the assessment by the instructors at the end of the course, the subjective assessment (by one of us), and the objective assessment derived from the recorded tape (Table 5). The data on diagnosis are missing, because they were not recorded on the tape. When the American Heart Association criteria are strictly applied only $7 \%$ and $1 \%$ respectively in both groups were able to perform correct cardiopulmonary resuscitation.
Table 5 Percentage of participants performing adequate cardiopulmonary resuscitation before and after the course and at the refresher course by self assessment, instructors' assessment, subjective assessment, and objective assessment

\begin{tabular}{llll}
\hline Assessement & $\begin{array}{l}\text { Before } \\
(n=10)\end{array}$ & $\begin{array}{l}\text { After } \\
(n=88)\end{array}$ & $\begin{array}{l}\text { Refresher course } \\
(n=68)\end{array}$ \\
\hline Self & 0 & 94 & 82 \\
Instructors' & 0 & 90 & 85 \\
Subjective & 0 & 65 & 44 \\
Objective & 0 & 7 & 1 \\
\hline
\end{tabular}

\section{Discussion}

The number of people attending refresher courses is astonishingly low. Because most of these participants are well motivated and interested, a bias in the data obtained in this group is inevitable, and "improves" the results. Before the course no participant was able to perform even a bad cardiopulmonary resuscitation. After the three evening sessions theoretical knowledge was good and was well retained at the refresher course. Since, however, people knew the date of the re-examination and would have studied our instruction booklet at home the actual level of knowledge may have been even lower.

The technique of palpating the carotid artery was surprisingly well retained after six months. The mean time needed to diagnose cardiopulmonary arrest was $42 \mathrm{~s}$ in both groups, which is quite long even when the time needed to palpate the carotid artery on both sides of the manikin to ensure that there is no pulse (at most $20 \mathrm{~s}$ ) is taken into account. The most common mistake in ventilation was the low number of ventilations/minute or an inadequate volume or both. Ventilation was notably worse when performed by people with dental prostheses since they generally leaked air; they performed better with mouth to nose ventilation. Some of the participants ventilated the manikin while chewing chewing-gum; this was discovered afterwards in the trachea of the manikin. Comparable events were reported by Shih et al. ${ }^{9}$ In cardiac massage the most common fault was the low number of compressions performed per minute. The reason for this finding is not always an incorrect rhythm but the time needed for ventilation, together with the time needed to search for the correct compression point, reduces the time available for massage.

At the end of the course and at the refresher course there was a large discrepancy between the candidate's own estimation of their performance $(98 \%$ and $82 \%$ thought themselves proficient), the assessment by the paramedical instructors ( $90 \%$ and $85 \%$ respectively), the subjective assessment $(65 \%$ and $44 \%$ respectively), and the objective assessment using recorded tape data ( $7 \%$ and $1 \%$ respectively). The most objective method of examining candidates on their car- 
diopulmonary resuscitation performance is therefore by using recording manikins, since subjective criteria grossly overestimate the practical performance level. Nevertheless, these objective figures are also exaggerated since ventilation with a volume of 0.71 or 1.81 is sufficient for cardiopulmonary arrest, as is a cardiac compression rate of 49 or 72 compression/minute. Our results agree wth those of Ramirez et al and Weaver $e t a l, 46$ but Mandel et al described opposite results. ${ }^{7}$

In our community we give a three session course; even so we cannot claim satisfactory results when the lay participants are re-examined. It would be worthwhile to compare our results, especially those after the refresher course with those obtained after a course held within three hours, as is the instruction method for instance in Seattle. ${ }^{10}$ Despite the problems and possible disappointing results, it is well known that cardiopulmonary resuscitation by lay people does save lives ${ }^{11}$ and improves the neurological outcome. ${ }^{12}$ In our forthcoming courses more attention will be paid to $(a)$ the diagnosis (reduction of the time needed for checking the conscious level and palpation of the carotid artery, which with training can be done within $30 \mathrm{~s}$ ); (b) call for help (to perform this immediately after the diagnosis of cardiopulmonary arrest has been established); (c) ventilation (to decrease the time taken for two ventilations and especially the time most people need to find the correct pressure point on the chest); and (d) massage (to increase the rate to 80 compressions/minute and to emphasise further the correct depth needed). It is advisable to provide refresher courses for lay people in cardiopulmonary resuscitation at least twice a year giving special attention to the above techniques.

We thank $\mathrm{Mr} \mathrm{Ph}$ van Elteren and $\mathrm{Mr}$ A G $M$ Dinkhuijsen for carrying out the analytical work. Part of this study was supported by a grant from the Netherlands Heart Foundation.

\section{References}

1 Kouwenhoven WB, Jude JR, Knickerbocker GG. Closed-chest cardiac massage. $\mathcal{F}$ AMA 1960; 173: 1064-7.

2 American Heart Association. Standards for cardiopulmonary resuscitation (CPR) and emergency cardiac care (ECC). FAMA 1974; 227 (suppl): 833-68.

3 American Heart Association. Standards and guidelines for cardiopulmonary resuscitation (CPR) and emergency cardiac care (ECC). FAMA 1980; 244: 453-509.

4 Ramirez AG, Weaver FJ, Raizner AE, Dorfman SB, Herrick KL, Gotto AM Jr. The efficiency of lay CPR instruction: an evaluation. Am $\mathcal{F}$ Public Health 1977; 67: 1093-5.

5 Tweed WA, Wilson E, Isfeld B. Retention of cardiopulmonary resuscitation skills after initial overtraining. Crit Care Med 1980; 8: 651-3.

6 Weaver FJ, Ramirez AG, Dorfman SB, Raizner AE. Trainees' retention of cardiopulmonary resuscitation. How quickly they forget. FAMA 1979; 241: 901-3.

7 Mandel LP, DeMers JL, Olsen MF, Cobb LA. Evaluation of instructional aspects of a citizen CPR training program [Abstract]. Circulation 1977; 55 (suppl III): 114.

8 Klinge J. Wanneer elke seconde telt. [When every second counts.] 's-Gravenhage, The Nethelands: Netherlands Heart Foundation.

9 Shih C, Tanaka T, Lam M, Palmer SC, Lau FYK. Mishaps of CPR: the case of the missing dental bridge [Letter]. $N$ Engl f Med 1982; 306: 1057.

10 Cobb LA, Werner JA, Trobaugh GB. Sudden cardiac death. I. A decade's experience with out-of-hospital resuscitation. Mod Concepts Cardiovasc Dis 1980; 49: 31-6.

11 Adgey AAJ, Nelson PG, Scott ME, et al. Management of ventricular fibrillation outside hospital. Lancet 1969; i: 1169-71.

12 Copley DP, Mantle JA, Rogers WJ, Russell RO Jr, Rackley CE. Improved outcome for prehospital cardiopulmonary collapse with resuscitation by bystanders. Circulation 1977; 56: 901-5. 